\title{
A global climatology of total columnar water vapour from SSM/I and MERIS
}

\author{
R. Lindstrot ${ }^{1}$, M. Stengel ${ }^{2}$, M. Schröder ${ }^{2}$, J. Fischer ${ }^{1}$, R. Preusker ${ }^{1}$, N. Schneider ${ }^{2}$, T. Steenbergen ${ }^{2}$, and \\ B. R. Bojkov ${ }^{3}$ \\ ${ }^{1}$ Institut für Weltraumwissenschaften, Freie Universität Berlin, Carl-Heinrich-Becker-Weg 6-10, 12165 Berlin, \\ Germany \\ ${ }^{2}$ Deutscher Wetterdienst, Satellite-Based Climate Monitoring, Dept. Climate and Environment, \\ Strahlenbergerstraße 13, 63067 Offenbach, Germany \\ ${ }^{3}$ ESA/ESRIN, Via Galileo Galilei, Casella Postale 64, 00044 Frascati, Italy
}

Correspondence to: R. Lindstrot (rasmus.lindstrot@wew.fu-berlin.de)

Received: 18 December 2013 - Published in Earth Syst. Sci. Data Discuss.: 24 January 2014

Revised: 13 May 2014 - Accepted: 16 May 2014 - Published: 16 June 2014

Abstract. A global time series of total columnar water vapour from combined data of the Medium Resolution Imaging Spectrometer (MERIS) onboard ESA's Environmental Satellite (ENVISAT) and the Special Sensor Microwave/Imager (SSM/I) onboard the satellite series of the US Defense Meteorological Satellite Program (DMSP) is presented. The unique data set, generated in the framework of the ESA Data User Element (DUE) GlobVapour project, combines atmospheric water vapour observations over land and ocean, derived from measurements in the near-infrared and the microwave range, respectively. Daily composites and monthly means of total columnar water vapour are available as global maps on rectangular latitude-longitude grids with a spatial resolution of $0.05^{\circ} \times 0.05^{\circ}$ over land and $0.5^{\circ} \times 0.5^{\circ}$ over ocean for the years 2003 to 2008 . The data are stored in NetCDF files and is fully compliant with the NetCDF Climate Forecast convention. Through the combination of high-quality microwave observations and near-infrared observations over ocean and land surfaces, respectively, the data set provides global coverage. The combination of both products is carried out such that the individual properties of the microwave and near-infrared products, in particular their uncertainties, are not modified by the merging process and are therefore well defined. Due to the global coverage and the provided uncertainty estimates this data set is potentially of high value for climate research. The SSM/I-MERIS TCWV data set is freely available via the GlobVapour project web page (www.globvapour.info) with associated doi:10.5676/DFE/WV_COMB/FP.

In this paper, the details of the data set generation, i.e. the satellite data used, the retrieval techniques and merging approaches, are presented. The derived level 3 products are compared to global radiosonde data from the GCOS upper air network (GUAN), showing a high agreement with a root-mean-square deviation of roughly $4.4 \mathrm{~kg} \mathrm{~m}^{-2}$ and a small wet bias well below $1 \mathrm{~kg} \mathrm{~m}^{-2}$. Furthermore, the data set is shown to be free of seasonal biases. The consistency of the MERIS and SSM/I retrievals is demonstrated by applying the MERIS retrieval to sun glint areas over ocean. 


\section{Introduction}

Water vapour is the most important greenhouse gas in the Earth atmosphere. It accounts for about $70 \%$ of the total atmospheric absorption of radiation and $60 \%$ of the total natural greenhouse effect in clear-sky cases (Kiehl and Trenberth, 1997; Trenberth and Kiehl, 2008). At the same time, water vapour is highly variable in space and time, as it is constantly brought into the atmosphere by evaporation, transported by advection and convection, and depleted by condensation and precipitation. These mechanisms result in both horizontal and vertical transport of latent heat, dominating the structure of tropospheric diabatic heating (Trenberth and Stepaniak, 2003a, b). Above the global oceans, an increase of tropospheric water vapour of about $1.2 \%$ per decade has been observed since the late 1980s (Trenberth and Smith, 2005; Trenberth et al., 2007). The water vapour feedback, i.e. the enhanced greenhouse effect due to increased humidity as a response to higher temperatures, is nowadays believed to be a comparatively strong and positive effect (e.g. Soden et al., 2002; Forster and Collins, 2004). Over the oceans, the absolute humidity in the lower atmosphere is closely linked to the near-surface air temperature, i.e. the water vapour changes at roughly the same rate as the saturated vapour pressure, as estimated from the Clausius-Clapeyron law (see, for example, O'Gorman and Muller, 2010). The situation over the land masses is more complicated. Here, the limited supply of water available for evaporation results in an overall weaker but regionally varying feedback.

While the radiative impact of water vapour and the watervapour-temperature feedback mechanism is mainly determined by the vertical profile of water vapour and the amount of humidity in the upper atmosphere, at the same time it is of high importance to have accurate knowledge of the total amount of water vapour in the vertical column of the atmosphere, which is closely linked to cloud amount, precipitation and the hydrological cycle as a whole (Soden et al., 2002; Allan et al., 2014). Accurate, long-term measurements of the total column of water vapour are therefore crucial for monitoring the temporal evolution and spatial distribution of humidity and its role in the hydrological cycle. Satellite measurements of the total column water vapour have the potential to provide the needed temporal and spatial coverage and resolution as well as retrieval accuracy to serve these purposes. Please note that a large number of different terms are used in the literature, all describing the same quantity, such as total column water vapour (TCWV), total precipitable water (TPW), integrated water vapour (IWV) or water vapour path (WVP). We will use the term TCWV throughout this paper.

A variety of techniques for the retrieval of TCWV from satellite data have been developed during the past decades. Above the global oceans, microwave observations provide reliable information on total column water vapour. Due to the comparably low emissivity of water surfaces in the microwave region, the variability of the top-of-the-atmosphere microwave signal is dominated by the emission by water in its gaseous and liquid phase in the atmosphere. A number of different microwave sensors - such as NASA's Advanced Microwave Scanning Radiometer for EOS (AMSRE) and the Advanced Microwave Sounding Unit (AMSU) or the Microwave Humidity Sounder (MHS) instruments, deployed on a variety of operational polar-orbiting satellites - are thus commonly used to measure profiles of water vapour as well as its vertical integral over the open ocean and for assimilating the measurements for numerical weather prediction (NWP) models. The longest available time series of microwave humidity observations is provided by the measurements of the SSM/I instrument series onboard the US Defense Meteorological Satellite Program (DMSP) satellites. Data from SSM/I-type instruments are available starting from 1987 and it is currently foreseen that they will be extended into the 2020s and even the 2030s through the DMSP programme and the EUMETSAT Polar System-Second Generation (EPS-SG), respectively, making them a valuable source for the generation of climate data records (CDRs).

Above land and sea ice, microwave measurements are affected by large and highly variable surface emissivities. In the infrared, the limited knowledge of the skin temperature and the emissivity of land surfaces results in high uncertainties of the water vapour amount in the lower troposphere, where the bulk of the vertically integrated water vapour amount is present. However, hyperspectral sounders such as IASI (e.g. Pougatchev et al., 2009) and AIRS (e.g. Susskind et al., 2003) provide valuable information on the vertical humidity profile down to a level close to the surface. The integral of the vertical column of water vapour is best represented when using differential optical absorption spectroscopy (DOAS) in the near-infrared or visible range. In contrast to infrared and microwave retrievals, here the information about TCWV is not carried by the thermal emission of the water vapour itself but instead by the absorption of solar radiation in spectral regions of water vapour absorption. Exploiting Beer's law, the water vapour column amount can be deduced from the transmittance, which is approximated by the ratio of an absorbing channel inside the absorption band and a spectrally close channel outside of the absorption band. Moderately to highly reflective surfaces, such as most land surface types in the near-infrared region, provide a high sensitivity to TCWV of such measurements. Over the dark ocean, this technique is not appropriate for the retrieval of TCWV. Spaceborne sensors, such as ESA's Medium Resolution Imaging Spectrometer (MERIS) or NASA's Moderate Resolution Imaging Spectroradiometer (MODIS), provide the needed measurements in the near infrared and have been successfully deployed for the retrieval of TCWV (Bennartz and Fischer, 2001; Gao and Kaufman, 2003; Albert et al., 2005; Lindstrot et al., 2012).

Since spaceborne observations of TCWV with global coverage and of a high quality are hard to get from a single 
instrument type alone, our aim is to use a combination of data sources to combine the strengths of the individual instruments. This strategy was pursued by the Global Water Vapour Project (GVaP), which completed a successful pilot phase and developed a global water vapour data set (NASA Water Vapour Project, NVAP; Randel et al., 1996) from a combination of microwave and infrared sensors and radiosondes. A reanalysis and extension of NVAP, NVAP-M as part of the NASA-MEaSUREs programme, was conducted in recent years and resulted in a climatology of total and layered humidity spanning 22 years (Vonder Haar et al., 2012).

In the framework of the ESA Data User Element (DUE) GlobVapour project, a related approach was pursued by combining measurement of MERIS and SSM/I. MERIS measurements were used to derive TCWV over land and coastal ocean, complemented by SSM/I observations over ocean to achieve global coverage at comparably high quality.

The GlobVapour project combined SSM/I-MERIS data set, comprised of global maps of daily composites and monthly means, is thus a unique combination of water vapour observations over land and ocean. Over land, the high spatial resolution of MERIS enables the generation of the products on a rectangular longitude-latitude grid with $0.05^{\circ} \times 0.05^{\circ}$ resolution. Over ocean, a $0.5^{\circ} \times 0.5^{\circ}$ resolution is provided. The data set in its current version ranges from 2003 through 2008 and it is foreseen that it will be extended to cover at least the full mission lifetime of MERIS, which ended in April 2012. The data are provided in NetCDF format via the project website (www.globvapour.info) and is fully compliant with the NetCDF Climate Forecast convention.

In the following sections, the data set is presented in detail, covering a description of the instruments as well as the input data versions used (Sect. 2). The individual retrieval techniques are described in Sect. 3, while the merged data set and its validation are covered in Sects. 4 and 5, respectively.

\section{Instrumentation and data provenance}

\subsection{The MERIS instrument}

MERIS is a programmable, medium-spectral-resolution, imaging spectrometer (Rast et al., 1999). It is 1 of 10 core instruments on the polar orbiter ENVISAT (Environmental Satellite, launched on 1 March 2002) flying at $800 \mathrm{~km}$ in a Sun-synchronous orbit with an Equator-crossing time of 10:00 (stable throughout the mission) descending node and 98.5 inclination. MERIS consists of five identical pushbroom imaging spectrometers, operating in the solar spectral range (390 to $1040 \mathrm{~nm}$ ), arranged in a fan shape configuration which covers a total field of view of $68.5^{\circ}$ and spans a swath width of around $1150 \mathrm{~km}$. The spectral dispersion is achieved by mapping the entrance slit of a grating spectrometer onto a CCD array. The integration time, instrument optics and CCD array resolution are adjusted such that MERIS has a spatial resolution of $260 \mathrm{~m} \times 300 \mathrm{~m}$ and a spectral sampling of $1.25 \mathrm{~nm}$. The instrument electronic data rate provides 15 channels which are programmable by ground command in width and in position. In the regular operation mode the spatial resolution is reduced by a factor of 4 along and across track ("reduced resolution" mode). In the "full resolution" mode, the full spatial resolution is transmitted. MERIS data of the third reprocessing of the level 1 archive was used for the generation of the water vapour fields. Compared to previous reprocessings of the MERIS archive, a new calibration and improved geolocation had the most important impacts on the level 1 products in terms of radiometry, geometry and flags for land/ocean/coastline classification (MERIS Quality Working Group, 2011). With respect to spatial resolution and spectral band setting in the near-infrared range, MERIS is related to the MODIS instrument. MODIS data therefore represent a well-suited candidate for the potential extension of the data set and bridging of the data gap occurring after the loss of ENVISAT (April 2012) and the launch of the Copernicus Sentinel-3 satellite (currently foreseen for late 2015), carrying the MERIS heritage Ocean and Land Colour Instrument (OLCI).

\subsection{The SSM/I instrument}

The SSM/I (Hollinger, 1991) is a passive, seven-channel, four-frequency microwave radiometer which is operated within the DMSP satellite series, flying on Sun-synchronous orbits at a nominal altitude of $830 \mathrm{~km}$. The SSM/I is a conical scanner with a nominal scan angle (satellite view angle with respect to nadir) of $45^{\circ}$, which corresponds to an Earth incidence angle of $53^{\circ}$. Of the four bands used, $19 \mathrm{GHz}$, $22 \mathrm{GHz}, 37 \mathrm{GHz}$ and $85 \mathrm{GHz}$, three have dual polarization $(19 \mathrm{GHz}, 37 \mathrm{GHz}$ and $85 \mathrm{GHz})$ while one does not (the $22 \mathrm{GHz}$ channel), resulting in seven channels. Depending on the channel, SSM/I has a footprint of a few tens of kilometres. The first SSM/I instrument was carried by the F08 satellite, launched in 1987; the last one was launched on F15 in December 1999. The SSM/I was replaced by the SSMIS (Special Sensor Microwave Imager/Sounder) starting from DMSP satellite F16. The available long-term data record of SSM/I observations together with its high sensitivity to atmospheric water vapour makes it a very valuable source for climate studies. The generation of the TCWV fields was based on intercalibrated SSM/I brightness temperatures of the F13 and F14 DMSP satellites (Andersson et al., 2010). The data were provided by CM SAF as an early release of the CM SAF SSM/I FCDR edition 1. The data are available at http://www.cmsaf.eu/wui and are referenced under DOI:10.5676/EUM_SAF_CM/FCDR_SSMI/V001. Other SSM/I FCDRs are described in Sapiano et al. (2013), Berg et al. (2013) or Semunegus (2011) and are available at http://www.ncdc.noaa.gov/cdr/operationalcdrs.html. SSM/I has been and is used in various applications for the retrieval of atmospheric water vapour using physical (e.g. Phalippou, 1996; Elsaesser and Kummerow, 2008) and semi-physical 
schemes based on a statistical interpretation of a training data set (e.g. Alishouse et al., 1990; Schlüssel and Emery, 1990; Schulz et al., 1993; Wentz, 1997).

\section{Retrieval techniques}

\subsection{TCWV retrieval over land and coastal ocean using MERIS}

The MERIS scheme for the retrieval of TCWV makes use of the differential absorption of solar radiation by atmospheric water vapour in the near-infrared spectral range. Since the retrieval is thus based on the analysis of surface-reflected solar radiation, the retrieval can only be applied during daytime and under clear-sky conditions. This limitation to clearsky scenes is likely to introduce a weak low bias in TCWV with respect to climatologies based on all-sky retrievals (e.g. Cess and Potter, 1987; Allan et al., 2003; Sohn and Bennartz, 2008; Mieruch et al., 2010).

Two channels of MERIS, located within and close by the shortwave end of the $\rho \sigma \tau$-absorption band at $900 \mathrm{~nm}$ are used for the approximation of the water vapour transmittance. The measurements are sensitive to water vapour over moderately to highly reflective underlying surfaces, such as the majority of land surface types: While vegetated surfaces appear dark in the visible range, due to the chlorophyll absorption, they are far less absorbing in the near-infrared range. Similar values are found for most non-vegetated surfaces with surface albedo levels above 0.2 (see Lindstrot et al., 2012, Fig. 4).

\subsubsection{MERIS cloud screening}

Due to the high albedo of clouds, the underlying atmosphere and the water vapour it contains are hidden to space-based observations in the near infrared. In cases of semitransparent clouds present in the field of view, part of the radiation penetrates through the clouds while still a significant fraction is reflected at the cloud itself, causing a reduction of the observed water vapour absorption. A potential correction of these effects, taking into account the MERIS-derived cloud height and optical depth as well as the tabulated surface reflectance, would only be possible at the expense of strongly increased retrieval uncertainties. Moreover, the MERIS product would be deprived of its most important strength, the high sensitivity to variations in the boundary layer humidity. The first mandatory pre-processing step in the MERIS processing chain is therefore the screening of all clouds.

The cloud detection is realized by the utilization of one of four different artificial neural networks (ANN), depending on whether the measurement is taken over an ocean, land, snow or ice surface. The ANNs were developed in the framework of the ESA MERIS Global Land Surface Albedomap project (Preusker et al., 2008). The ANNs use the majority of MERIS spectral bands, including the oxygen A-band channel which is sensitive to the presence of clouds and their height (e.g. Preusker and Lindstrot, 2009). In addition, the input to the ANNs are

- the surface pressure, calculated from the terrain elevation and assuming a standard pressure of $1013 \mathrm{hPa}$ at sea level;

- the observation geometry; and

- the central wavelength of the MERIS oxygen A-band channel.

The latter is needed to account for the variable spectral centre wavelength of the absorption channel (Delwart et al., 2007; Lindstrot et al., 2010), while knowledge of the surface pressure is required to optimize the use of the pressure information carried by the oxygen absorption.

The ANNs were trained with radiative transfer simulations of MERIS radiances, performed with the Matrix Operator Model (MOMO; Fell and Fischer, 2001; Hollstein and Fischer, 2012). The training databases covered the complete range of observation conditions and geophysical conditions possible for each regime. The output of each ANN is the probability of cloudiness, ranging from 0 to 1 .

After applying the ANNs, pixels exhibiting a cloud probability of larger than an empirically determined threshold were masked out. A cloud probability threshold of 0.2 was found to simultaneously maximize the fraction of correctly identified clouds and minimize the number of clear-sky cases falsely classified as cloudy. In order to exclude cloud edges, areas identified as cloudy were artificially extended by additionally masking a zone of two MERIS pixels $(\approx 2 \mathrm{~km})$ surrounding each cloudy pixel. Since the MERIS instrument was radiometrically and spectrally stable throughout its lifetime, we do not expect any artificial trend or jumps in the water vapour record that cloud potentially be caused by a changing sensitivity to clouds.

\subsubsection{MERIS water vapour retrieval}

The TCWV retrieval itself is described in detail in Lindstrot et al. (2012). The algorithm is divided into two individual steps, starting with a determination of the surface reflectance in MERIS band 14 at $885 \mathrm{~nm}$ (window channel) and 15 at $900 \mathrm{~nm}$ (absorption channel) and a subsequent iterative optimization of TCWV by minimizing the cost function, represented by the absolute difference between the modelled (see below) and observed ratios of MERIS bands 15 and 14 .

After correcting the measured MERIS band ratio for differences in the surface reflectance between 885 and $900 \mathrm{~nm}$, the forward simulation of the MERIS bands is based on a calculation of the water vapour absorption optical depths. These are calculated using an advanced $k$-distribution technique (Bennartz and Fischer, 2000; Doppler et al., 2014) with the absorption line parameters extracted from the HITRAN2008 
database (Rothman et al., 2009). The effects of temperature and pressure on the calculated optical depths are considered by using a digital elevation model and ERA Interim $2 \mathrm{~m}$ temperatures. This secondary correction of the absorption optical depth is the only influence of reanalysis data on the MERIS water vapour retrieval.

In order to account for the influence of scattering on the measured band ratio, a scattering correction factor is calculated from pre-calculated look-up tables at each retrieval iteration step. Here, over land, a continental aerosol model is used, assuming a constant optical depth of 0.15 at a wavelength of $900 \mathrm{~nm}$. Over the coastal ocean, a maritime aerosol model is used instead. Over both land and ocean, the aerosols are assumed to reside in the boundary layer. The cost function minimization is achieved by a simple secant method and is regarded successful as soon as the cost function falls below the sensor noise level. Except for the ERA Interim $2 \mathrm{~m}$ temperature, the algorithm does not rely on any sort of prior knowledge.

The uncertainty of the retrieved value of TCWV is calculated after the final iteration step by taking into account uncertainties introduced by instrumental effects such as sensor noise and uncertainties in background knowledge of the influencing parameters such as surface albedo, aerosol optical depth, aerosol vertical distribution, temperature profile and surface pressure. Especially over dark surfaces, the aerosol optical depth and vertical distribution were found to be the largest sources of uncertainty, since static average values with rather large error bars were assumed globally. In contrast, the retrieval uncertainties introduced by the temperature profile and surface pressure uncertainties were found to be of secondary order. For a detailed description of the uncertainty calculation, please see Lindstrot et al. (2012).

\subsection{TCWV retrieval over ocean using SSM/I}

(Semi-)statistical TCWV retrievals over oceans, based on recalibrated and homogenized radiance data records from SSM/I observations, are available from, for example, Remote Sensing Systems (RSS - Wentz, 1997) and the Satellite Application Facility on Climate Monitoring (CM SAF - Schlüssel and Emery, 1990; Andersson et al., 2010; Schröder et al., 2013). Within the framework of the GlobVapour project the objective was to utilize a physical retrieval scheme which provides an uncertainty estimate at pixel level. Such physical retrievals are described in, for example, Phalippou (1996) and Elsaesser and Kummerow (2008). Here, the onedimensional variational retrieval (1D-Var) scheme developed at ECMWF (Phalippou, 1996) was utilized, including adaptations made by Deblonde (2001). The latter enable the application of the scheme to SSM/I, while the initial application of the scheme was for the SSMIS microwave imager/sounder and AMSU (Advanced Microwave Sounding Unit). The scheme is freely available from the Satellite Application Facility on Numerical Weather Prediction (NWP
SAF) at http://research.metoffice.gov.uk/research/interproj/ nwpsaf/1dvar/index.html. The scheme is used to derive TCWV from brightness temperatures of SSM/I over ice-free ocean. The best estimate of the atmospheric state, composed of atmospheric temperature, moisture and liquid cloud condensate as well as surface variables temperature and wind speed, is determined by an iterative adjustment of the state vector to match the simulated satellite radiances with the measurements. The term "best estimate" refers to the optimal estimation theory (Rodgers, 2000) and describes the state vector $\boldsymbol{x}$ that minimizes the cost function $J$ taking into account the errors in the background information $\mathbf{B}$ and in the measurement $\mathbf{R}$ :

$$
\begin{aligned}
J & =1 / 2\left(\boldsymbol{x}-\boldsymbol{x}_{\mathrm{b}}\right)^{\mathrm{T}} \mathbf{B}^{-1}\left(\boldsymbol{x}-\boldsymbol{x}_{\mathrm{b}}\right), \\
& +1 / 2(\boldsymbol{y}-H(\boldsymbol{x}))^{\mathrm{T}} \mathbf{R}^{-1}(\boldsymbol{y}-H(\boldsymbol{x})) ;
\end{aligned}
$$

$H$ denotes the observation operator (here based on radiative transfer calculations) and $\boldsymbol{y}$ the measurements. The matrices $\mathbf{B}$ and $\mathbf{R}$ are used as included in the used 1D-Var package. With this methodology, a retrieval uncertainty is calculated for each of the control vector elements. In this framework, the 1D-Var scheme uses ERA Interim atmospheric and surface fields valid at $12: 00 \mathrm{UTC}$ on a $0.5^{\circ}$ longitude-latitude grid as background information for all observations processed on a specific day, with the exception of the background information for water vapour, for which spatially resolved, 3-year averages are used. Scenes with significant precipitation and/or cloud ice are filtered out by the application of an internal scattering index filter.

\section{Combined data set}

In order to achieve a global time series of TCWV with high accuracy above both land and ocean, the retrievals of MERIS above land and SSM/I above ocean were combined to produce daily composites and monthly means on a rectangular longitude-latitude grid. Above land, the $1 \mathrm{~km}^{2}$ resolution of the MERIS product enables a spatial resolution of $0.05^{\circ} \times 0.05^{\circ}$, obtained by averaging the available clear-sky retrievals. Above ocean, the spatial resolution was chosen to be $0.5^{\circ} \times 0.5^{\circ}$ due to the larger footprint of SSM/I. The SSM/I and MERIS retrievals have reduced quality over coastal areas relative to the respective retrievals over ocean and land. The coastal areas are filled with MERIS-derived TCWV. Due to the forenoon orbit of ENVISAT (Equator-crossing time at 10:00) and the fact that the MERIS retrieval relies on measurements of the reflected solar radiation in the near-infrared spectral range, the resulting time series over land is a cloudfree, forenoon climatology. In order to establish consistency between land and ocean, only morning measurements (descending swath) of SSM/I onboard the DMSP satellites F13 and F14 (Equator-crossing time between 06:00 and 09:00; see Sapiano et al. (2013) for details) were used for the retrieval of TCWV over ocean. As microwave measurements of 
TCWV are possible under cloudy and clear-sky conditions, TCWV was calculated with and without cloud screening.

\subsection{Daily composites}

The daily composites of TCWV combine the MERIS measurements above land and coastal ocean with the daytime measurements of descending SSM/I orbits over the open ocean. Over land and the coastal ocean, the content of each grid box is calculated from a weighted average of the contributing $n$ MERIS pixels, with the weight $w_{i}=1 / \sigma_{i}^{\text {rel }^{2}}$ of each contributing pixel defined by its relative uncertainty $\sigma_{i}^{\mathrm{rel}}=\sigma_{i} / \mathrm{TCWV}_{i}$, with $\sigma_{i}$ being the uncorrelated uncertainty:

$\mathrm{TCWV}=\left(\sum_{i=1}^{n} w_{i} \mathrm{TCWV}_{i}\right) / \sum_{i=1}^{n} w_{i}$

The number of MERIS pixels contributing to a grid box is up to 30 in the tropics and drops to 20 at $50^{\circ}$ latitude and 10 at $70^{\circ}$ latitude.

In the case of purely random errors and thus for averaging $n$ measurements, the uncertainty $\sigma$ of the average value is

$\sigma=1 /\left(\sum_{i=1}^{n} 1 / \sigma_{i}^{2}\right)^{1 / 2}$

This results in a reduction of uncertainty if more measurements are averaged. However, within a grid box, the level 2 uncertainties of the contributing measurements cannot be regarded as uncorrelated, since critical forward-modelling assumptions, such as the aerosol type, will affect all individual measurements in the grid box in a correlated way. In order to account for this, a more conservative approach was taken by calculating the resulting grid box uncertainty as the average uncertainty of the contributing measurements:

$\sigma=\sum_{i=1}^{n} \sigma_{i} / n$

Therefore, the uncertainty values provided for each daily composite grid box over land and coastal ocean provide an upper boundary of the uncertainty. In addition, the standard deviation of the contributing MERIS measurements is provided in each grid box as it provides information about the sub-grid variability of TCWV.

Over ocean, SSM/I TCWV retrievals are sampled per $0.5^{\circ} \times 0.5^{\circ}$ grid box together with the calculated retrieval uncertainty. These data are then oversampled by a factor of 10 in order to be combined with the MERIS data to provide a single data field containing both data sources. To enhance the usability of the combined SSM/I-MERIS data set, it is available with a reduced global resolution of $0.5^{\circ} \times 0.5^{\circ}$.

Figure 1 shows an example of a global SSM/I-MERIS daily composite of TCWV and its associated uncertainty
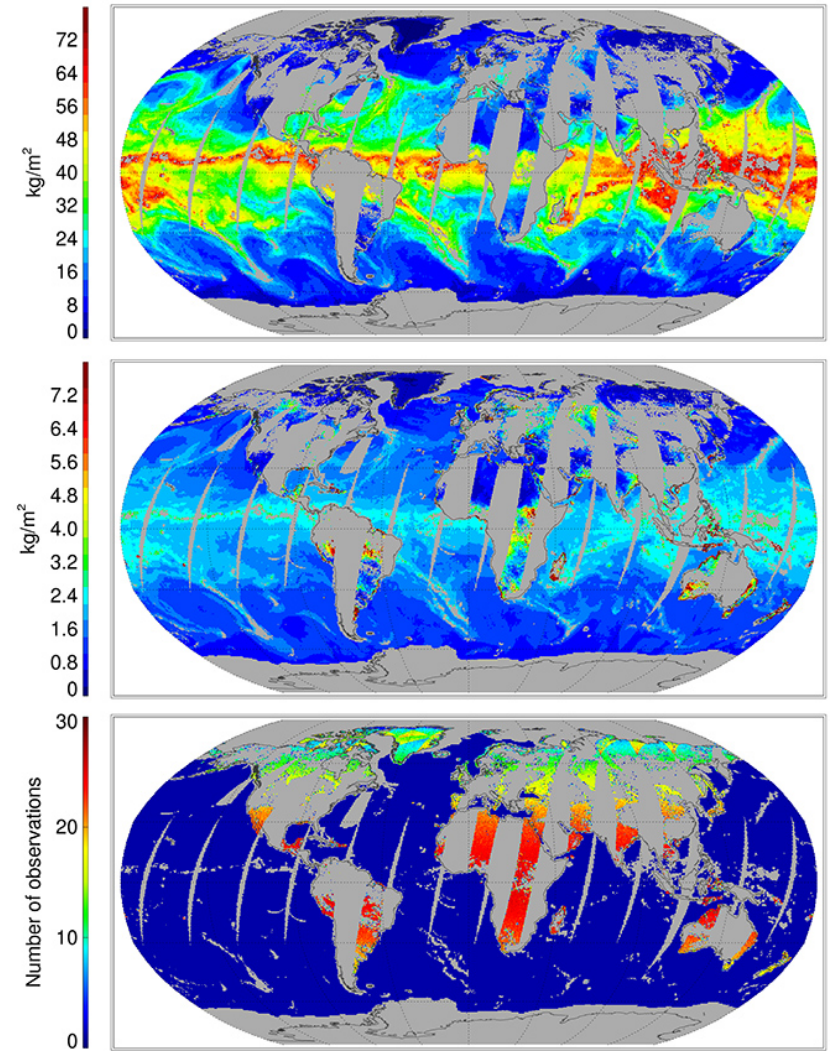

Figure 1. Example of daily composite of TCWV (top), associated uncertainty (middle) and number of observations used (10 May 2003).

(note the change in colour scale). Over land, the smaller swath of MERIS and the limitation to clear-sky scenes results in a lower coverage compared to the open ocean, observed by SSM/I, where only heavily precipitating regions are masked out. The number of single observations used for the generation of the daily composite values is shown in the bottom panels, with the number of MERIS observations used to fill each grid box varying between 0 and 30, while generally single SSM/I measurements were used over ocean.

Figure 2 shows a close-up of the Mediterranean Sea area for a daily composite from 2 May 2003. It shows a smooth transition of the water vapour field between land and ocean as well as a somewhat increased uncertainty in the coastal areas, where MERIS measurements are used to fill the SSM/I gaps. The figure also reveals the high sensitivity of MERIS for small-scale variations in the water vapour field, such as that visible over western Turkey.

\subsection{Monthly means}

The monthly mean water vapour over land in each grid box is calculated from the average of all available daily values. The resulting monthly mean over land and coastal ocean can be regarded as the cloud-free, forenoon monthly average of 

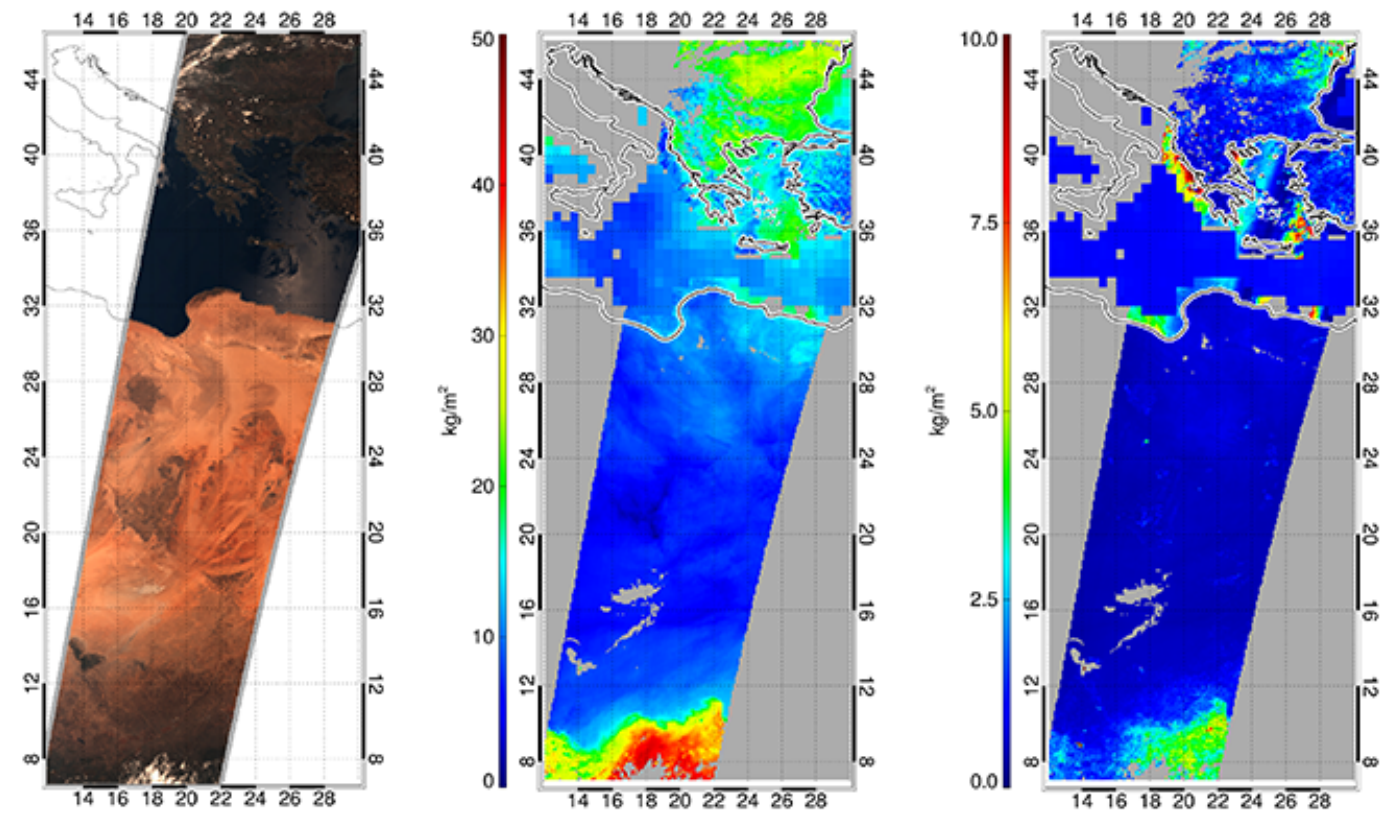

Figure 2. MERIS RGB image of scene over the Mediterranean Sea from 2 May 2003 (left) and close-up of daily composite of TCWV (middle) and uncertainty of TCWV (right) from MERIS and SSM/I measurements.

TCWV. Similar to the daily uncertainties, the associated uncertainty of the monthly mean value is derived from the average uncertainty of the contributing daily values. Again, the standard deviation among the daily values is provided in addition to reflect the temporal variability of TCWV during the course of the month.

The average of all swath-based SSM/I retrievals build the monthly mean TCWV over ocean. Accordingly, a standard deviation is provided based on the same swath-based data points, whose associated uncertainty measures are averaged to build a monthly mean uncertainty representative for each grid box.

As an example, Fig. 3 shows the global distribution of monthly mean TCWV for January and June 2003 and the associated uncertainty for both months. Over ocean, the absolute uncertainty follows the general distribution of TCWV and is in the region of $5 \%$ in the tropics and mid-latitudes. Over coastal waters, where the monthly averaged TCWV is based on MERIS measurements, the uncertainty is increased (see for instance the Adriatic Sea, Caspian Sea or the Aegean). Over land, the uncertainty can exceed $10 \%$ in regions with comparably low surface reflectance. Over highly reflective surfaces, such as desert or snow regions, the uncertainty is strongly reduced. The number of single observations used for the generation of the monthly mean values is shown in the bottom panels. While over ocean an almost constant sampling is achieved, over land the number of valid observations is strongly affected by the presence of clouds.

\section{Validation}

\subsection{Validation against independent data sets}

The individual, swath-based level 2 retrievals of MERIS and SSM/I were thoroughly validated against a number of ground-based reference data sets. In the case of MERIS, Lindstrot et al. (2012) reported a globally small wet bias $(\approx$ $1 \mathrm{~kg} \mathrm{~m}^{-2}$ ) and bias-corrected root-mean-square deviations (RMSD) of $3.7 \mathrm{~kg} \mathrm{~m}^{-2}$ (global AERONET sun photometer measurements), $2.7 \mathrm{~kg} \mathrm{~m}^{-2}$ (global GUAN radiosondes), $1.3 \mathrm{~kg} \mathrm{~m}^{-2}$ (ARM site microwave radiometer measurements) and $2.1 \mathrm{~kg} \mathrm{~m}^{-2}$ (German ground-based GPS data), based on analysing all available collocations within the years 2003 to 2005. With respect to typical uncertainties of spaceborne TCWV retrievals, the MERIS TCWV retrieval over land can therefore be regarded to be of high accuracy and precision. In the case of SSM/I, Fig. 4 shows a comparison against the ground-based microwave radiometer measurements taken at the Nauru ARM site between 1998 and 2008. Here, a distance of less than $1^{\circ}$ between the ARM site and a SSM/I footprint, completely covering ocean surfaces, was the collocation criterion. The bias and the bias-corrected RMSD of $-0.48 \mathrm{~kg} \mathrm{~m}^{-2}$ and $1.8 \mathrm{~kg} \mathrm{~m}^{-2}$, respectively, reveal the high accuracy and precision of the SSM/I TCWV retrieval.

On level 3 basis, the complete time series spanning 6 years was evaluated by monitoring the bias and RMSD with respect to the GUAN radiosonde observations. The collocation contains pairs of SSM/I and GUAN as well as pairs of MERIS and GUAN data. However, the evaluation results will be dominated by the MERIS and GUAN pairs. Figure 5 

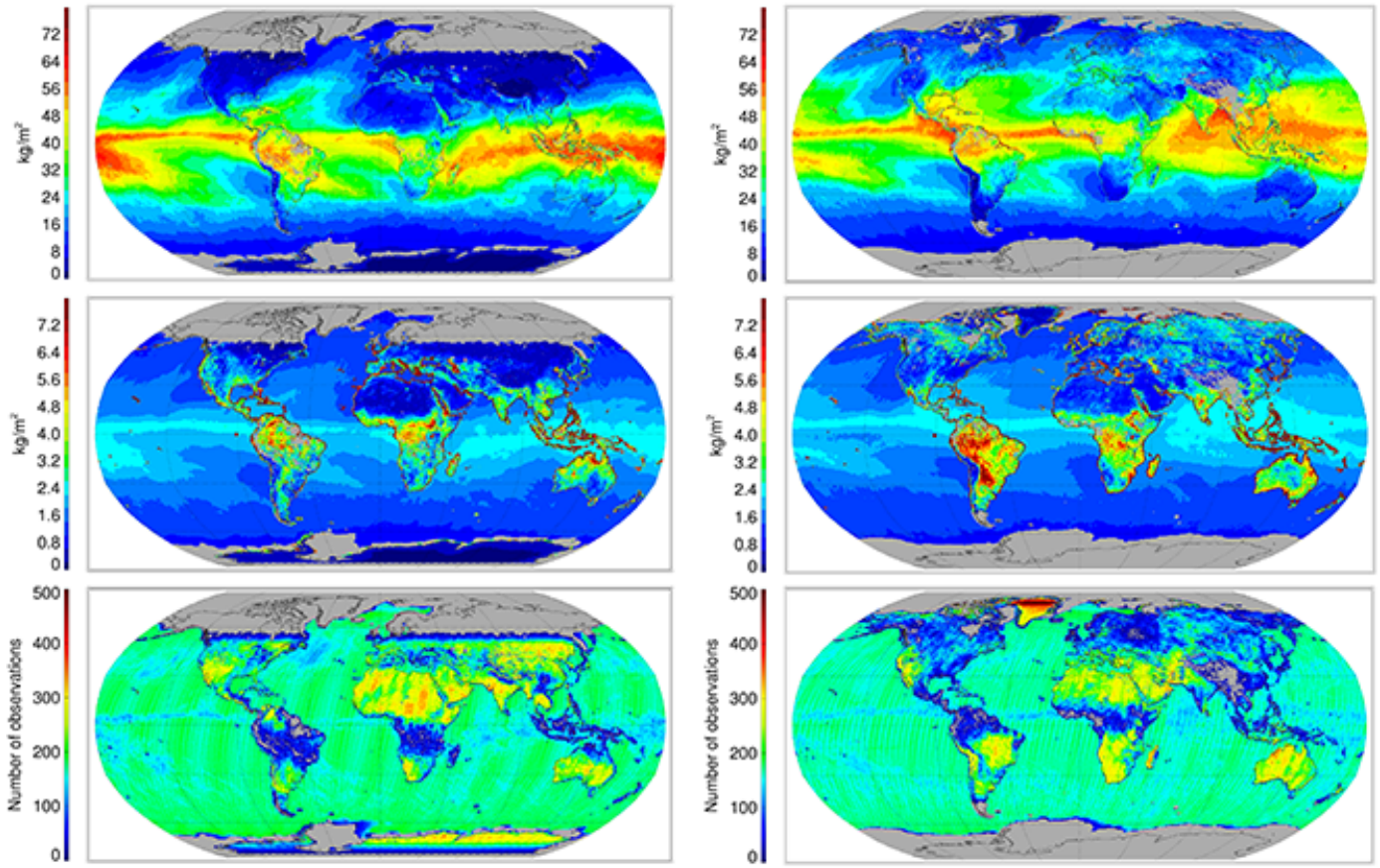

Figure 3. Monthly mean TCWV (top), associated uncertainty (middle) and number of observations used (bottom) for January (left) and June (right) 2003.

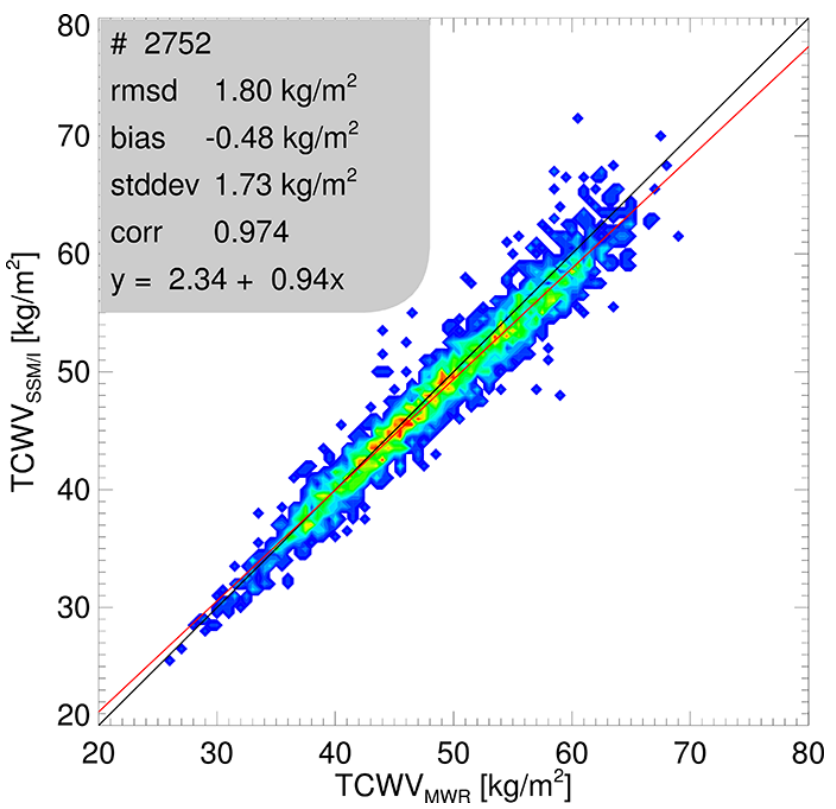

Figure 4. Normalized frequency of occurrence for comparison of SSM/I-derived TCWV against ARM Nauru microwave radiometer data for the period 1998-2008. Relative frequency of occurrence is shown in different colours, with blue indicating low frequency and red high frequency of occurrence. The top left box specifies sample size, root-mean-square deviation, bias, standard deviation, and offset and slope of linear best fit. Colours correspond to 1 (blue) to $\geq 12$ (red) cases per $0.5 \mathrm{~kg} \mathrm{~m}^{-2} \times 0.5 \mathrm{~kg} \mathrm{~m}^{-2}$ bin. shows the resulting time series of bias and RMSD, globally averaged over all GUAN stations. For these comparisons, for each radiosonde ascent, the closest neighbouring grid box of the SSM/I-MERIS monthly mean fields on a regular lat.long. grid was selected. No further temporal criteria were applied. However, the monthly mean of the radiosonde and the selected SSM/I-MERIS grid box both were required to be based on at least 15 individual observations in the particular month in order to be considered for the comparison. There is no evidence of any jumps in the difference between SSM/IMERIS and GUAN TCWV. A small wet bias can be observed which is generally below $1 \mathrm{~kg} \mathrm{~m}^{-2}$ but approaches $2 \mathrm{~kg} \mathrm{~m}^{-2}$ for some months after 2006. The bias-corrected RMSD is between 4 and $5 \mathrm{~kg} \mathrm{~m}^{-2}$ throughout the time series. Neither the bias nor the standard deviation exhibit any seasonal signal. Figure 6 shows the scatterplot of SSM/I-MERIS and GUAN monthly mean TCWV values, generated by using all individual GUAN stations for the complete 6-year time series, resulting in 5492 collocations. In agreement with the findings shown in Fig. 5, the RMSD is around $4.4 \mathrm{~kg} \mathrm{~m}^{-2}$, with a small wet bias of $0.7 \mathrm{~kg} \mathrm{~m}^{-2}$. The ocean collocations seem to exhibit a slightly higher bias. Despite the general limits of comparing spaceborne observations to radiosonde measurements, these findings indicate a generally high accuracy and precision and temporal homogeneity of the SSM/I-MERIS TCWV data set. 


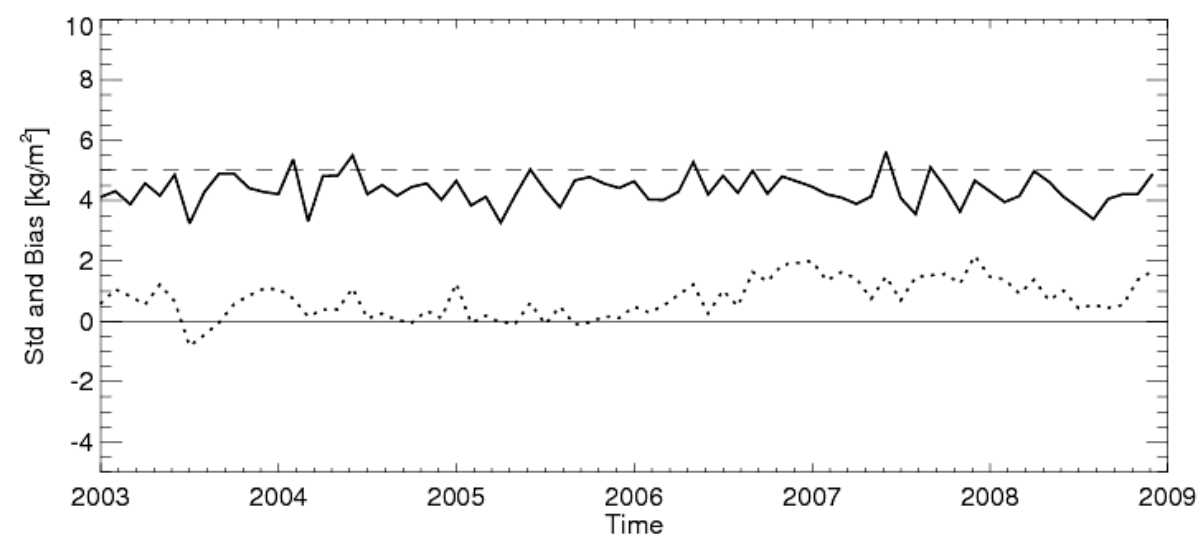

Figure 5. Time series of bias (dotted line) and bias-corrected RMSD (solid line) of SSM/I-MERIS monthly mean TCWV with respect to GUAN, averaged over all GUAN stations.

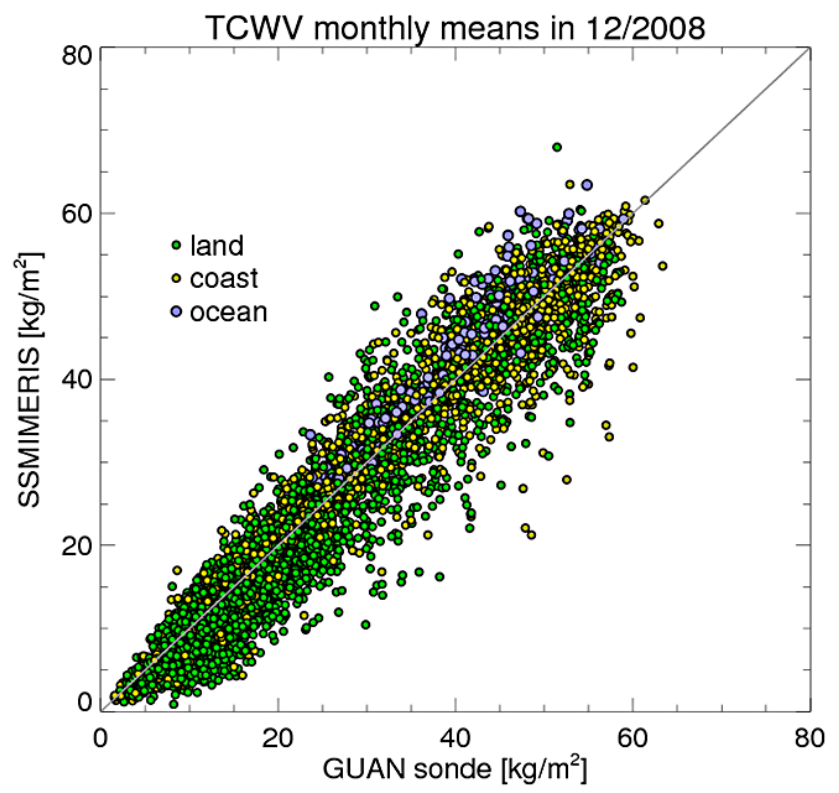

Figure 6. Scatterplot of SSM/I-MERIS monthly mean TCWV vs. individual GUAN stations for the period 2003-2009 (5492 collocated cases, with $67 \%$ land, $29 \%$ coast and $4 \%$ ocean cases). Resulting root-mean-square deviation is $4.4 \mathrm{~kg} \mathrm{~m}^{-2}$, bias is $0.7 \mathrm{~kg} \mathrm{~m}^{-2}$.

\subsection{Consistency between MERIS and SSM/I retrievals}

In order to assess the presence of a potential bias between the retrieval algorithms, the MERIS TCWV retrieval was applied to cloud-free ocean areas exhibiting a significant fraction of directly reflected sun light. In contrast to measurements over the dark ocean, for sun glint geometries the sensitivity of the MERIS measurements to the full vertical column of water vapour is established by a signifant fraction of light being reflected at the lower boundary of the atmosphere. Due to the ENVISAT forenoon orbit and the MERIS observation geometry, a significant amount of sun-glint-affected pixels appears in the eastern part of the tropical and subtropical section of each orbit, provided that ocean pixels are present here.

In order to perform the scattering correction of MERIS measurements, the surface reflectance was calculated using the ECMWF wind speed for parametrizing the sea surface roughness (Cox and Munk, 1954; Koepke, 1984). Afterwards, the retrieval is performed in the same way as over land, with an assumption of a fixed aerosol optical thickness of 0.1 in the bright, inner part of the sun glint areas. Although this assumption might have a large error in some areas downwind of aerosol source regions, it has a weak impact on the water vapour retrieval due to highly reflective ocean surface, causing the surface term to dominate the signal.

There are two difficulties to be noted for the comparison of SSM/I and MERIS retrievals over ocean:

1. For the MERIS retrieval, the same scattering correction factors as over land are used, calculated based on the assumption of a Lambertian surface. Since this assumption over ocean is inappropriate, increased uncertainties are to be expected.

2. The observation time difference of $2-4 \mathrm{~h}$ hours potentially introduces a bias.

One month (July 2007) of MERIS TCWV retrievals over open ocean was used to compare to SSM/I cloud-free retrievals. In order to compensate for the differing footprint sizes and observation times, the comparison was performed on a $0.5^{\circ}$ grid. Figure 7 shows a close-up of the Atlantic Ocean for measurements of SSM/I and MERIS on 9 July 2007, as well as the ocean surface reflectance for the MERIS viewing geometry. As expected, both retrievals show a rather high agreement for most of the sun glint areas, shown as unshaded elliptic regions, while larger deviations can be found over the dark ocean, shown as shaded regions.

Figure 8 shows the resulting difference of the two retrievals $\left(\mathrm{TCWV}_{\text {MERIS }}-\mathrm{TCWV}_{\mathrm{SSM} / \mathrm{I}}\right)$ as a function of the ocean surface reflectance, based on analysing one complete 

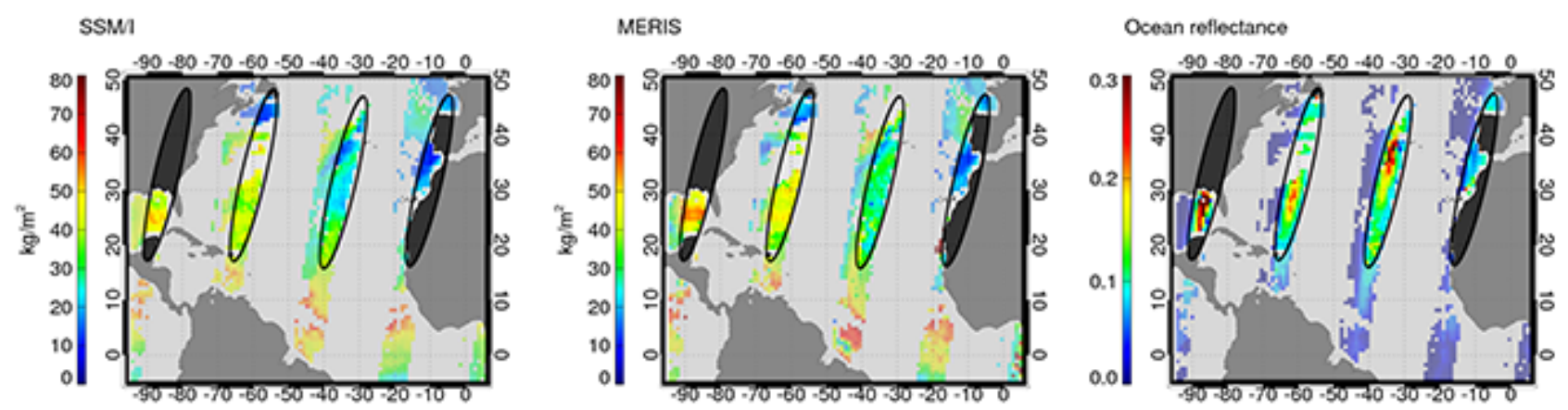

Figure 7. Close-up of daily composites of TCWV from SSM/I (left) and MERIS (middle) over ocean and ocean surface reflectance at 900 nm for MERIS viewing geometry (right), on 9 July 2007. Plots only show data where both MERIS and SSM/I retrievals are valid. Unshaded elliptic areas indicate regions where MERIS retrieval is reliable.

month of collocated measurements. A large bias of MERIS TCWV is found for dark ocean surfaces, hinting at an inadequate scattering correction scheme. The bias decreases with increasing ocean surface reflectance (and scattering becomes less important), with values below $1 \mathrm{~kg} \mathrm{~m}^{-2}$ and a Pearson product-moment correlation coefficient around 0.85 for reflectances higher than 0.15 . Despite the above limitations in the comparisons of both retrievals, this hints at a high consistency among the two completely independent data sources. The fact that, on average, TCWV values derived from MERIS measurements over ocean are actually higher than those derived from SSM/I measurements seems to contradict the findings of the comparison of both retrievals against GUAN radiosonde data (see Sect. 5.1 and Fig. 6). These opposite biases observed in the two comparisons hint at the effect of natural limits with respect to the homogeneity of the different data sets, imposed by, for example, the differing observation times, footprint sizes and sensitivities to disturbing influences, such as the inaccurate description of surface properties or the presence of undetected clouds in the field of view. The magnitude of the differences found, however, demonstrates that, on average, these limitations have a rather weak effect on the spatial homogeneity of the SSM/IMERIS data set.

\section{Conclusions}

The ESA DUE GlobVapour combined SSM/I-MERIS data set of total columnar water vapour in its current version spans the years 2003 to 2008 and consists of daily composites of MERIS forenoon TCWV observations over cloud-free land and coastal ocean and SSM/I all-sky morning observations over ocean, as well as monthly averages. The data set is available in a high resolution $\left(0.05^{\circ} \times 0.05^{\circ}\right)$ and at a coarse resolution version $\left(0.5^{\circ} \times 0.5^{\circ}\right)$. To provide consistent resolution, $\mathrm{SSM} / \mathrm{I}$ is oversampled in the former case and MERIS is averaged in the latter case.

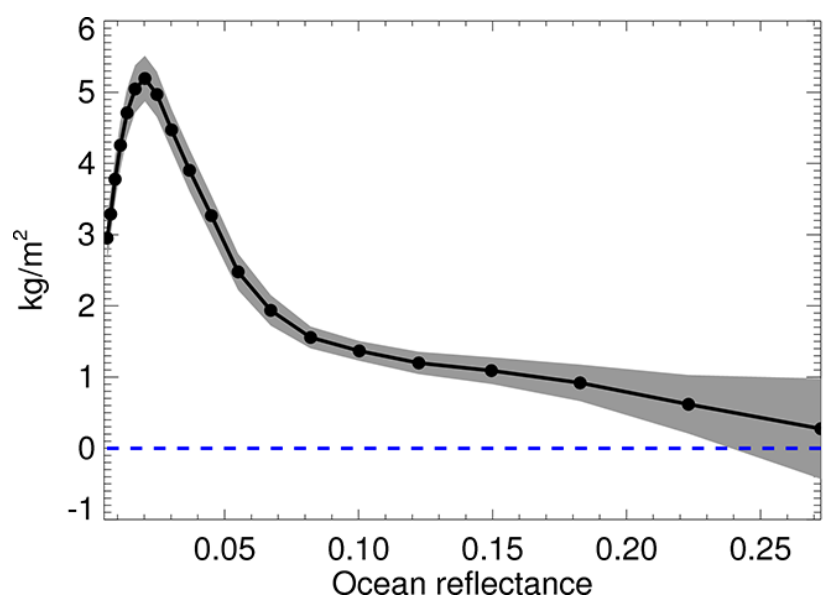

Figure 8. Difference of MERIS TCWV and SSM/I TCWV over ocean (MERIS - SSM/I) as a function of ocean surface reflectance, analysed from 1 month of collocated MERIS and SSM/I observations (July 2007). Grey shaded area indicates standard deviation of bias, analysed from bootstrapping statistics.

The validation studies showed high agreements with GUAN radiosonde data of water vapour, with a weak wet bias of $0.74 \mathrm{~kg} \mathrm{~m}^{-2}$ and a standard deviation of $4.4 \mathrm{~kg} \mathrm{~m}^{-2}$. On global average, no indication of any seasonal bias of the MERIS-SSM/I data set was found. However, due to the clear-sky-only sampling over land, this might not be fulfilled regionally, especially in regions with strongly varying cloud cover during the year, such as the tropics. The effect of daytime-only sampling remains to be assessed. Due to the generally higher temperatures during daytime, slightly higher levels of humidity can be expected compared to climatologies based on day and night sampling. By applying the MERIS retrieval algorithm to ocean areas, the consistency of the two data sources could be verified. Over sun glint regions, where the MERIS TCWV retrieval is of similar quality as over land, only a small positive bias of MERIS TCWV with respect to SSM/I retrievals was found. However, 
it is important to note that the limitation to clear-sky scenes over land might introduce an inconsistency with respect to the all-sky retrievals over ocean as described, for example, in Mieruch et al. (2010).

The combination of both data sources was carried out such that the individual properties of the microwave and nearinfrared products, in particular their uncertainties, were not modified and are therefore well defined. Due to its known and defined quality, its global coverage and spatial consistency as well as its high spatial resolution over land, this unique data set allows for climate studies on both land and ocean. Process studies are possible as well, although limited by the reduced coverage over land areas. The SSM/I-MERIS TCWV data set is freely available at www.globvapour.info.

An extension of the data set is possible to cover at least the full ENVISAT lifetime (2002-2012). With respect to future satellite missions, the upcoming Ocean and Land Colour Instrument (OLCI) onboard the Sentinel-3 satellites, flying in an ENVISAT-like orbit with the same Equator-crossing time, will provide similar measurements in the near-infrared water vapour absorption band (Diedrich et al., 2013). In order to fill the gap between MERIS and OLCI and enhance the data coverage, data of the MODIS instrument on the Terra satellite (flying in forenoon orbit) represent a logical candidate to be used after careful intercalibration of the different instruments. With respect to the SSM/I instrument, it is currently foreseen to extend the SSM/I series into at least the 2020s and with the microwave imager instrument (MWI) planned to be deployed onboard the Eumetsat Polar SystemSecond Generation (EPS-SG) satellites allowing to further extend SSM/I-type measurements into the 2030s. Other instruments, such as NASA's recently launched Global Precipitation Measurement (GPM) Microwave Imager (GMI), are well suited additional candidates for a water vapour climatology constructed by combining observations of multiple instruments. The combined data set presented here could therefore be a demonstrator for a potential future time series covering at least a few decades of water vapour observations over land and ocean.

Acknowledgements. This work was performed in the framework of the ESA DUE GlobVapour project (ESA contract number 22696/09/I-OL). The NWP SAF is kindly acknowledged for providing the SSM/I 1D-Var software package. The CM SAF kindly provided an intercalibrated SSM/I data set.

Edited by: G. König-Langlo

\section{References}

Albert, P., Bennartz, R., Preusker, R., Leinweber, R., and Fischer, J.: Remote Sensing of Atmospheric Water Vapor Using the Moderate Resolution Imaging Spectroradiometer (MODIS), J. Atmos. Ocean. Tech., 22, 309-314, 2005.
Alishouse, J. C., Snyder, S. A., Jennifer, V., and Ferraro, R. R.: Determination of oceanic total precipitable water from the SSM/I, IEEE T. Geosci. Remote, 28, 811-816, 1990.

Allan, R. P., Ringer, M. A., and Slingo, A.: Evaluation of moisture in the Hadley Centre climate model using simulations of HIRS water-vapour channel radiances, Q. J. Roy. Meteor. Soc., 129, 3371-3389, doi:10.1256/qj.02.217, 2003.

Allan, R. P., Liu, C., Zahn, M., Lavers, D., Koukouvagias, E., and Bodas-Salcedo, A.: Physically Consistent Responses of the Global Atmospheric Hydrological Cycle in Models and Observations, Surv. Geophys., 35, 533-552, doi:10.1007/s10712-0129213-z, 2014.

Andersson, A., Fennig, K., Klepp, C., Bakan, S., Graß1, H., and Schulz, J.: The Hamburg Ocean Atmosphere Parameters and Fluxes from Satellite Data - HOAPS-3, Earth Syst. Sci. Data, 2, 215-234, doi:10.5194/essd-2-215-2010, 2010.

Bennartz, R. and Fischer, J.: A modified k-distribution approach applied to narrow band water vapour and oxygen absorption estimates in the near infrared, J. Quant. Spectrosc. Ra., 66, 539-553, 2000.

Bennartz, R. and Fischer, J.: Retrieval of columnar water vapour over land from back-scattered solar radiation using the Medium Resolution Imaging Spectrometer (MERIS), Remote Sens. Environ., 78, 271-280, 2001.

Berg, W. K., Sapiano, M. R. P., Horsman, J., and Kummerow, C. D.: Improved Geolocation and Earth Incidence Angle Information for a Fundamental Climate Data Record of the SSM/I Sensors., IEEE T. Geosci. Remote, 51, 1504-1513, 2013.

Cess, R. D. and Potter, G. L.: Exploratory studies of cloud radiative forcing with a general circulation model, Tellus A, 39, 460-473, doi:10.1111/j.1600-0870.1987.tb00321.x, 1987.

Cox, C. and Munk, W.: Measurement of the Roughness of the Sea Surface from Photographs of the Sun's Glitter, J. Opt. Soc. Am., 44, 838-850, 1954.

Deblonde, G.: NWP SAF User's Guide: Standalone 1D-var scheme for the SSM/I, SSMIS and AMSU, NWPSAF-MO-UD-001 Version 1.0, 2001.

Delwart, S., Preusker, R., Bourg, L., Santer, R., Ramon, D., and Fischer, J.: MERIS inflight spectral calibration, Int. J. Remote. Sens., 28, 479-496, 2007.

Diedrich, H., Preusker, R., Lindstrot, R., and Fischer, J.: Quantification of uncertainties of water vapour column retrievals using future instruments, Atmos. Meas. Tech., 6, 359-370, doi:10.5194/amt-6-359-2013, 2013.

Doppler, L., Preusker, R., Bennartz, R., and Fischer, J.: k-bin and kIR: k-distribution methods without correlation approximation for non-fixed instrument response function and extension to the thermal infrared-Applications to satellite remote sensing, J. Quant. Spectrosc. Ra., 133, 382-395, doi:10.1016/j.jqsrt.2013.09.001, 2014.

Elsaesser, G. S. and Kummerow, C. D.: Toward a Fully Parametric Retrieval of the Nonraining Parameters over the Global Oceans, J. Applied Meteorol. Clim., 47, 1599, doi:10.1175/2007JAMC1712.1, 2008.

Fell, F. and Fischer, J.: Numerical simulation of the light field in the atmosphere-ocean system using the matrix-operator method, J. Quant. Spectrosc. Ra., 3, 351-388, 2001. 
Forster, P. D. F. and Collins, M.: Quantifying the water vapour feedback associated with post-Pinatubo cooling, Clim. Dynam., 23, 207-214, 2004.

Gao, B.-C. and Kaufman, Y. J.: Water vapor retrievals using Moderate Resolution Imaging Spectroradiometer (MODIS) near-infrared channels, J. Geophys. Res., 108, 4389, doi:10.1029/2002JD003023, 2003.

Hollinger, J. P.: DMSP Special Sensor Microwave Imager Calibration/Validation, NRL Final Rep., Vol. I, Tech. rep., Nav. Res. Lab., Washington, DC, 1991.

Hollstein, A. and Fischer, J.: Radiative transfer solutions for coupled atmosphere ocean systems using the matrix operator technique, J. Quant. Spectrosc. Ra., 113, 536-548, doi:10.1016/j.jqsrt.2012.01.010, 2012.

Kiehl, J. and Trenberth, K. E.: Earth's Annual Global Mean Energy Budget, B. Am. Meteorol. Soc., 78, 197-208, 1997.

Koepke, P.: Effective reflectance of oceanic whitecaps, Appl. Optics, 23, 1816-1824, 1984.

Lindstrot, R., Preusker, R., and Fischer, J.: The empirical correction of stray light in the MERIS oxygen A band channel, J. Atmos. Ocean. Tech., 27, 1185-1194, 2010.

Lindstrot, R., Preusker, R., Diedrich, H., Doppler, L., Bennartz, R., and Fischer, J.: 1D-Var retrieval of daytime total columnar water vapour from MERIS measurements, Atmos. Meas. Tech., 5, 631646, doi:10.5194/amt-5-631-2012, 2012.

MERIS Quality Working Group: MERIS 3rd data reprocessing, Software and ADF updates, Tech. Rep. A879.NT.008.ACRI-ST, ACRI, 2011.

Mieruch, S., Schröder, M., Noël, S., and Schulz, J.: Comparison of monthly means of global total column water vapor retrieved from independent satellite observations, J. Geophys. Res.-Atmos., 115, D23310, doi:10.1029/2010JD013946, 2010.

O'Gorman, P. A. and Muller, C. J.: How closely do changes in surface and column water vapor follow Clausius-Clapeyron scaling in climate change simulations?, Environ. Res. Lett., 5, 025207, doi:10.1088/1748-9326/5/2/025207, 2010.

Phalippou, L.: Variational retrieval of humidity profile, wind speed and cloud liquid-water path with the SSM/I: Potential for numerical weather prediction, Q. J. Ror. Meteor. Soc., 122, 327-355, 1996.

Pougatchev, N., August, T., Calbet, X., Hultberg, T., Oduleye, O., Schlüssel, P., Stiller, B., Germain, K. St., and Bingham, G.: IASI temperature and water vapor retrievals - error assessment and validation, Atmos. Chem. Phys., 9, 6453-6458, doi:10.5194/acp9-6453-2009, 2009.

Preusker, R. and Lindstrot, R.: Remote sensing of cloud-top pressure using moderately resolved measurements within the oxygen A band - a sensitivity study, J. Appl. Meteorol. Clim., 48, 15621574, 2009.

Preusker, R., Hünerbein, A., Fischer, J., Brockmann, C., and Krämer, U.: MERIS GLOBAL LAND SURFACE ALBEDO MAPS - ATBD CLOUD DETECTION, Algorithm theoretical basis document, Freie Universität Berlin, 2008.

Randel, D. L., Vonder Haar, T. H., Ringerud, M. A., Stephens, G. L., Greenwald, T. J., and Combs, C. L.: A new global water vapor dataset, B. Am. Meteorol. Soc., 77, 1233-1246, 1996.

Rast, M., Bezy, J. L., and Bruzzi, S.: The ESA Medium Resolution Imaging Spectrometer MERIS - A review of the instrument and its mission, Int. J. Remote Sens., 20, 1681-1702, 1999.
Rodgers, C.: Inverse Methods for Atmospheric Sounding: Theory and Practice, World Scientific, London, 2000.

Rothman, L., Gordon, I., Barbe, A., Benner, D., Bernath, P., Birk, M., Boudon, V., Brown, L., Campargue, A., Champion, J.-P., Chance, K., Coudert, L., Dana, V., Devi, V., Fally, S., Flaud, J.M., Gamache, R., Goldman, A., Jacquemart, D., Kleiner, I., Lacome, N., Lafferty, W., Mandin, J.-Y., Massie, S., Mikhailenko, S., Miller, C., Moazzen-Ahmadi, N., Naumenko, O., Nikitin, A., Orphal, J., Perevalov, V., Perrin, A., Predoi-Cross, A., Rinsland, C., Rotger, M., Simeckova, M., Smith, M., Sung, K., Tashkun, S., Tennyson, J., Toth, R., Vandaele, A., and Auwera, J. V.: The HITRAN 2008 molecular spectroscopic database, J. Quant. Spectrosc. Ra., 110, 533-572, doi:10.1016/j.jqsrt.2009.02.013, 2009.

Sapiano, M. R. P., Berg, W. K., McKague, D. S., and Kummerow, C. D.: Toward an Intercalibrated Fundamental Climate Data Record of the SSM/I Sensors, IEEE T. Geosci. Remote, 51, 1492-1503, doi:10.1109/TGRS.2012.2206601, 2013.

Schlüssel, P. and Emery, W. J.: Atmospheric water vapour over oceans from SSM/I measurements, Int. J. Remote Sens., 11, 753766, doi:10.1080/01431169008955055, 1990.

Schröder, M., Jonas, M., Lindau, R., Schulz, J., and Fennig, K.: The CM SAF SSM/I-based total column water vapour climate data record: methods and evaluation against re-analyses and satellite, Atmos. Meas. Tech., 6, 765-775, doi:10.5194/amt-6-765-2013, 2013.

Schulz, J., Schluessel, P., and Grassl, H.: Water vapour in the atmospheric boundary layer over oceans from SSM/I measurements, Int. J. Remote Sens., 14, 2773-2789, doi:10.1080/01431169308904308, 1993.

Semunegus, H.: Remote Sensing Systems Version-6 Special Sensor Microwave/Imager Fundamental Climate Data Record, Climate Algorithm Theoretical Basis Document CDRP-ATBD-0100, Climate Data Record (CDR) Program, 2011.

Soden, B. J., Wetherald, R. T., Stenchikov, G. L., and Robock, A.: Global Cooling After the Eruption of Mount Pinatubo: A Test of Climate Feedback by Water Vapor, Science, 296, 727-730, doi:10.1126/science.296.5568.727, 2002.

Sohn, B.-J. and Bennartz, R.: Contribution of water vapor to observational estimates of longwave cloud radiative forcing, J. Geophys. Res.-Atmos., 113, D20107, doi:10.1029/2008JD010053, 2008.

Susskind, J., Barnet, C. D., and Blaisdell, J. M.: Retrieval of atmospheric and surface parameters from AIRS/AMSU/HSB data in the presence of clouds, IEEE T. Geosci. Remote, 41, 390-409, 2003.

Trenberth, K. E. and Stepaniak, D. P.: Covariability of Components of Poleward Atmospheric Energy Transports on Seasonal and Interannual Timescales, J. Climate, 16, 3691-3705, 2003a.

Trenberth, K. E. and Stepaniak, D. P.: Seamless Poleward Atmospheric Energy Transports and Implications for the Hadley Circulation, J. Climate, 16, 3706-3722, 2003b.

Trenberth, K. E., Fasullo, J. T., and Smith, L.: Trends and variability in column-integrated atmospheric water vapor, Clim. Dynam., 24, 741-758, doi:10.1007/s00382-005-0017-4, 2005.

Trenberth, K. E., Jones, P. D., Ambenje, P., Bojariu, R., Easterling, D., Klein Tank, A., Parker, D., Rahimzadeh, F., Renwick, J. A., Rusticucci, M., Soden, B., and Zhai, P.: Observations: Surface and Atmospheric Climate Change. In: Climate Change 2007: The Physical Science Basis. Contribution of Working Group I 
to the Fourth Assessment Report of the Intergovernmental Panel on Climate Change, edited by: Solomon, S., Qin, D., Manning, M., Chen, Z., Marquis, M., Averyt, K. B., Tignor, M., and Miller, H. L., Cambridge University Press, Cambridge, United Kingdom and New York, NY, USA, 2007.

Trenberth, K. E., Fasullo, J. T., and Kiehl, J.: Earth's global energy budget, B. Am. Meteorol. Soc., 90, 311-323, doi:10.1175/2008BAMS2634.1, 2008.
Vonder Haar, T. H., Bytheway, J. L., and Forsythe, J. M.: Weather and climate analyses using improved global water vapor observations, Geophys. Res. Lett., 39, L15802, doi:10.1029/2012GL052094, 2012.

Wentz, F.: A well-calibrated ocean algorithm for special sensor microwave/imager, J. Geophys. Res., 102, 8703-8718, 1997. 